\title{
Construction of Interface Dipoles by Surface Doping and Their Role in the Open Circuit Voltage in Polymer Solar Cells
}

\author{
Shiyu $\mathbf{L i}^{\mathrm{a}}$ \\ Xinbo Wen ${ }^{\mathrm{a}}$ \\ Jiadong Zhou ${ }^{\mathrm{a}}$ \\ Nan Zheng ${ }^{a}$ \\ Linlin Liu ${ }^{a}$ (1) \\ Zengqi Xie ${ }^{* a}$ (i) \\ a State Key Laboratory of Luminescent Materials and Devices, Institute of Polymer
Optoelectronic Materials and Devices, Guangdong Provincial Key Laboratory of
Luminescence from Molecular Aggregates, South China University of Technology, No
381 Wushan Road, Guangzhou 510640, P. R. China \\ msxiez@scut.edu.cn
}

Received: 26.11.2019

Accepted after revision: 15.01.2020

DOI: 10.1055/s-0040-1702933; Art ID: 190022oa

License terms: $(9)(1) \ominus(-)$

(c) 2019. The Author(s). This is an open access article published by Thieme under the terms of the Creative Commons Attribution-NonDerivative-NonCommercial-License, permitting copying and reproduction so long as the original work is given appropriate credit. Contents may not be used for commercial purposes, or adapted, remixed, transformed or built upon. (https://creativecommons.org/licenses/by-nc-nd/4.0/).

Abstract A kind of dipolar interface is realized by surface doping of poly-(3,4-ethylenedioxythiophene) (PEDOT) with tetrafluoro-tetracyano-quinodimethane (F4TCNQ). PEDOT is in situ synthesized by electrochemical polymerization of 3,4-ethylenedioxythiophene (EDOT) on an indium tin oxide (ITO) electrode, and then F4TCNQ is spin-coated atop the PEDOT layer. Because the LUMO of F4TCNQ is lower than the HOMO of PEDOT, the spontaneous electron transfer from PEDOT to F4TCNQ results in a bilayered structure of PEDOT cations and F4TCNQ anions. Thus, a permanent interfacial dipole is formed in the surfacedoping system. The surface doping not only enhances the conductivity of PEDOT, but also increases the surface work function of the electrode. The dipolar film is applied as the anode interface in polymer solar cells (PSCs), and the results show that such an interface dipole plays a very important role in the open circuit voltage $\left(V_{\text {oc }}\right)$ of the PSCs.

Key words interfaces, charge transfer, dipoles, solar cells, surface doping

\section{Introduction}

Polymer solar cells (PSCs) have drawn increasing attention as a new kind of green and renewable energy technology. ${ }^{1-8}$ With the quick development of light-absorbing active materials, ${ }^{9-14}$ great efforts have been made on the interfacial engineering of devices in recent years. ${ }^{15-17}$ For a long time poly(3,4-ethylenedioxythiophene):polystyrene sulfonate (PEDOT:PSS) was commonly used as the anode buffer layer in conventional PSCs due to its proper work function (WF),
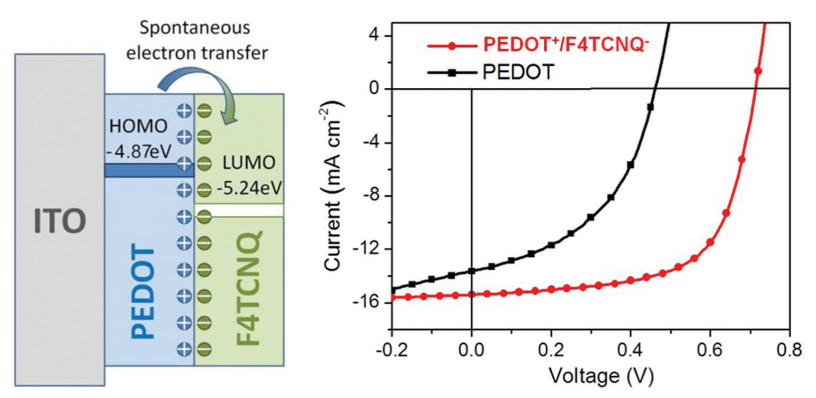

high transparency in the visible light region, and excellent air stability. ${ }^{18}$ However, the acidic PEDOT:PSS may etch the ITO electrode slowly due to the reaction with PSS, which can change the indium tin oxide (ITO)/PEDOT:PSS interface from ohmic to blocking, making it a primary source of degradation in PSCs. ${ }^{19,20}$ For example, unencapsulated P3HT:PCBM solar cell devices with PEDOT:PSS show a rapid decay of the short circuit current. $^{21}$ In order to solve this problem, various approaches have been reported, including introducing another buffer layer beneath PEDOT:PSS, ${ }^{22-24}$ posttreatment of PEDOT:PSS, ${ }^{25,26}$ doping PEDOT:PSS, ${ }^{27,28}$ or replacing PEDOT:PSS. ${ }^{29,30}$

The contact between the electrode and the active layer in PSCs is of essential importance, and the proper WF of the electrode is expected to form ohmic contacts in the device to reduce the energy barrier of the interface. The WF of the electrode is usually tuned by surface modification with dipolar molecules, such as a polyelectrolyte, which is attributed to the formation of surface dipoles. ${ }^{13,31-33}$ Such a surface dipole is originated from the partial electron transfer between the electrode and the surface modification layer. ${ }^{34,35}$ Other materials like perylene diimides ${ }^{36}$ and $C_{60}$ surfactants ${ }^{37}$ have also been reported to build surface dipoles in PSCs and improve device property. Indeed, the orientation of the dipolar units on the surface of the electrode is one of the important factors to tune the surface WF. ${ }^{33,36,38}$ Recently, our research group reported a dipolar film with a layered structure of anions and cations fabricated by in situ electrochemical reduction of a cross-linked perylene bisimide thin film, which was applied as a cathode interlayer in PSCs. ${ }^{39}$ Due to the reduced surface WF of the dipolar film, the open circuit voltage $\left(V_{\text {oc }}\right)$ of the PSCs was greatly increased from 0.56 to $0.75 \mathrm{~V}$.

Electrochemical polymerization (ECP) is a novel method for fabricating cross-linked thin films, which have been widely applied as an active layer in polymer light-emitting diodes (PLEDs), ${ }^{40,41}$ PSCs, ${ }^{42,43}$ supercapacitors (SCs), ${ }^{44}$ electrochromic devices (ECs), ${ }^{45}$ and so on. Such a cross-linked thin film 
possesses many advantages, such as controllable thickness, insolubility in common solvents, and so on, which are benefits to be used as an electrode modification layer. Indeed, it is ideal to apply a robust ECP film as the underlining interlayer to avoid the destruction of this layer during the solution processing of the active layer. Furthermore, ECP films can be easily doped for enhanced conductivity and tunable WF, to adapt to the requirement of the contact with the active layer in PSCs. ${ }^{46,47}$

In this work, we report a dipolar thin film of PEDOT with surface doping by tetrafluoro-tetracyano-quinodimethane (F4TCNQ), and the application of such a thin film to replace PEDOT:PSS as an anode modification layer in PSCs. F4TCNQ is one of the most widely used and most effective p-type dopants due to its strong electron-accepting ability and the extended $\pi$-system. ${ }^{48-50}$ It has been applied in the photoactive layer to fill trap states and improve fill factor (FF), ${ }^{51}$ and also used to dope the anode interface PEDOT:PSS to enhance its efficiency. ${ }^{52}$ Herein, the neutral PEDOT thin film was deposited on an ITO electrode by in situ ECP through the cyclic voltammetry (CV) method, and then a F4TCNQ thin layer was spin-coated atop the PEDOT layer. Because the LUMO of F4TCNQ is lower than the HOMO of PEDOT, ${ }^{53-55}$ the spontaneous electron transfer from PEDOT to F4TCNQ results in a bilayer structure of PEDOT cations and F4TCNQ anions. Thus, a permanent interfacial dipole is formed in the surface-doping system. The surface-doping strategy not only avoids the direct contact of ITO with the acidic species that is beneficial for the stability of the device, but also increases the surface WF of the electrode. The dipolar film was applied as the anode interface in PSCs, and a very close relationship between the surface dipole of the anode and the open circuit voltage $\left(V_{\text {oc }}\right)$ was demonstrated.

\section{Results and Discussion}

3,4-Ethylenedioxythiophene (EDOT) is a kind of electrochemical active monomer that was used to synthesize the conducting polymer PEDOT by electrochemical oxidation on the surface of an ITO electrode. ${ }^{54}$ The ECP process of PEDOT was performed via CV using tetrabutylammonium hexafluorophosphate $\left(\mathrm{TBAPF}_{6}\right)$ as the supporting electrolyte in acetonitrile $(A C N)$ solvent. Specific information about the ECP process can be found in the Supporting Information. The CV curve in Figure S2a showed that the electric current increased as scanning cycles increased, meaning the increase of film thickness. We measured the thickness of ECP PEDOT films using a Step profiler, as shown in Figure S2b, which showed a linear positive correlation of scanning cycles and film thickness. The PEDOT thin film was transparent when the film thickness is less than $25 \mathrm{~nm}$. Indeed, the PEDOT thin film was proved to be partially electrochemically doped according to the absorption properties compared with the doped films fabricated with the potentiostatic method (Figure S3). Such a partially doped state is a benefit to maintain high conductivity of the ECP thin film for application as a hole transporting layer in devices, which will be discussed in the following sections.

F4TCNQ has a deep LUMO level of $-5.24 \mathrm{eV},{ }^{55}$ which is energetically lower than the HOMO level of PEDOT $(-4.87 \mathrm{eV}) .^{53}$ F4TCNQ solution of $1 \mathrm{mg} / \mathrm{mL}$ in the mixture of dichloromethane (DCM) and tetrahydrofuran (THF) (1:4 by volume), a pale yellow solution, was spin-coated onto PEDOT at $3000 \mathrm{r} / \mathrm{min}$. And then the color of the film changed to ultra-light green, which was the color of F4TCNQ anions according to the literature. ${ }^{55}$ The thickness of the F4TCNQ layer was calculated by the difference of the thicknesses of PEDOT and the dipolar film, which was under $4 \mathrm{~nm}$. Since it was small and not precise, we used the thickness of PEDOT to represent the dipolar film. Surface doping is facilitated by charge transfer from the HOMO level of PEDOT to the LUMO of the F4TCNQ molecule. Then ionic layers of PEDOT ${ }^{+}$and F4TCNQ $^{-}$were built, and a permanent interface dipole moment was formed between the two layers, which is called a dipolar film in this work. The dipolar film was stable and insoluble in organic solvents. The principle of the formation of the interface dipole is shown in Figure 1.

Figure 2a shows the UV-vis absorption spectra of the pristine F4TCNQ thin film and the dipolar film. As can be seen, relative to the pristine F4TCNQ film, there are new absorption bands located at around 380 and $670 \mathrm{~nm}$ in the dipolar film, which verified the formation of $\mathrm{F}^{\mathrm{T} C N \mathrm{~N}^{-} \text {, }}$ resulting from the spontaneous electron transfer from PEDOT. ${ }^{55}$ As discussed above, the PEDOT film is in a partially

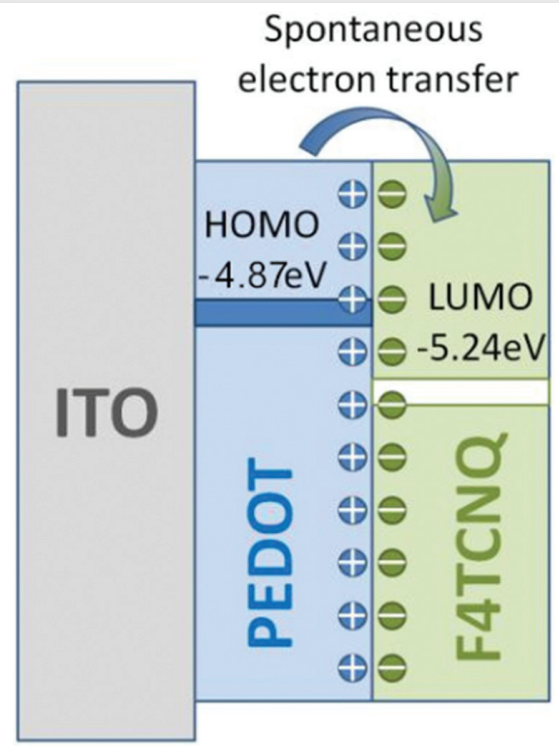

Figure 1 Schematic of interface dipole formed between PEDOT and F4TCNQ layers for the spontaneous electron transfer due to the LUMO of F4TCNQ is energetically lower than the HOMO of PEDOT. 

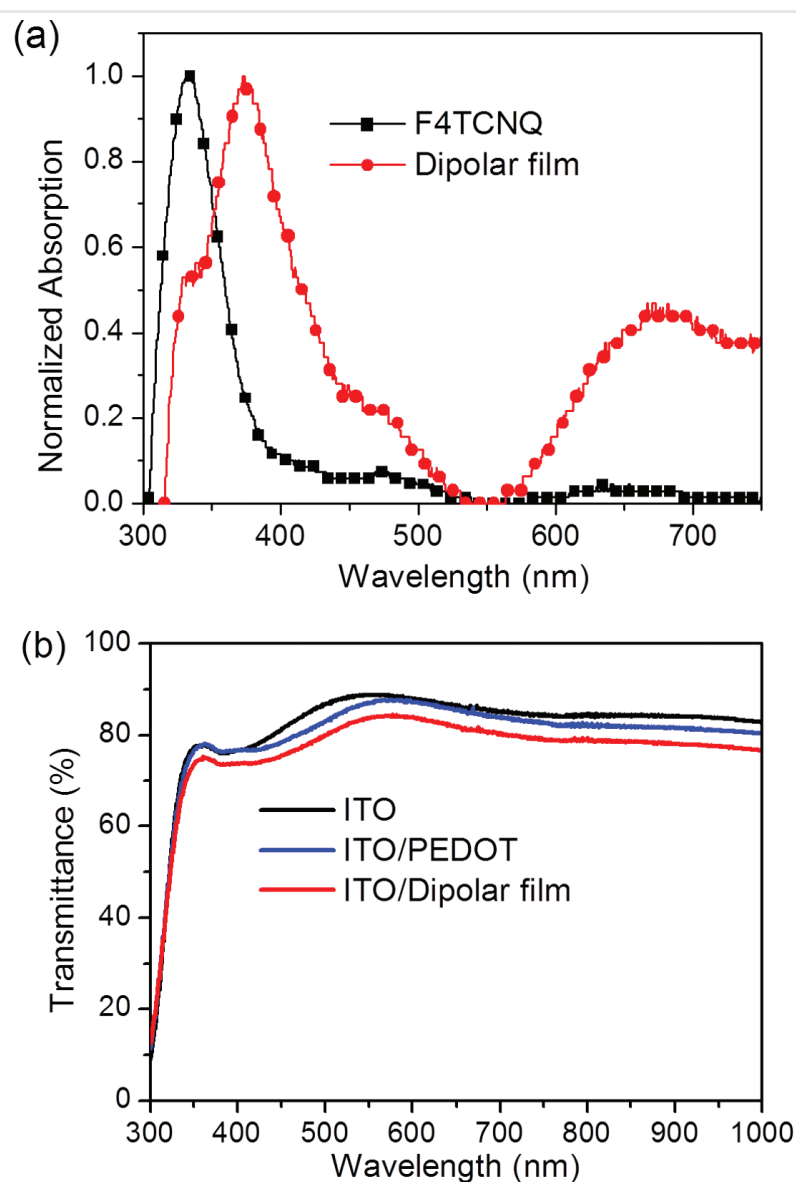

Figure 2 (a) Normalized UV-vis absorption spectra of the F4TCNQ film and dipolar film. (b) Transmittance spectra of ITO, ITO/PEDOT, and ITO/dipolar film.

doped state, thus, the absorption of this layer was relatively low in the visible region, giving very high transparency of the dipolar film. As shown in Figure 2b, the transparency of the dipolar film is more than $75 \%$ in most of the visible-light region, which is slightly lower than that of the bare ITO.

The morphological properties of the dipolar film and PEDOT film were investigated by atomic force microscopy (AFM), and the results are shown in Figure 3a, b. The rootmean-square (RMS) roughness of the dipolar film was $6.60 \mathrm{~nm}$, which is smaller than that of the PEDOT film $(8.73 \mathrm{~nm})$. The rough surface of the PEDOT film is attributed to the high polymerization rate of EDOT under the conditions used in this work. The surface roughness reduced greatly after the film was coated with a F4TCNQ layer, which is beneficial for the formation of uniform thin films of active layers in further application in devices. The wettability of the films was also investigated and the results are given in Figure S4. The dipolar film is more hydrophobic with a water contact angle of $61.6^{\circ}$ when compared with the film of PEDOT $\left(49.3^{\circ}\right)$, which would improve the compatibility
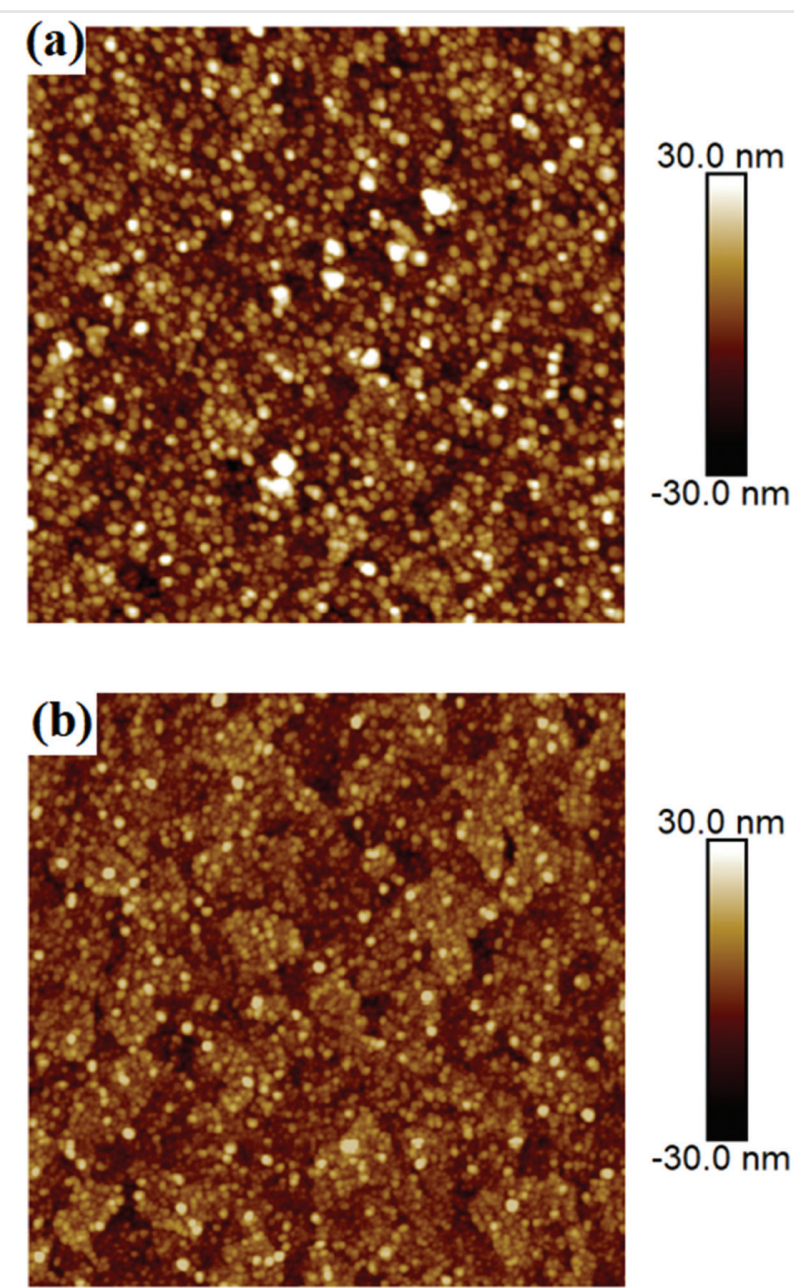

Figure 3 AFM images of (a) ECP PEDOT and (b) the dipolar film. The scan size was $4 \mu \mathrm{m} \times 4 \mu \mathrm{m}$.

between the dipolar film and organic active layers in devices. The conductivity of the dipole film and PEDOT was tested using the four-point probe method. The dipole film had the conductivity of $8.90 \times 10^{-2} \mathrm{~S} / \mathrm{m}$, which is slightly higher than the value of PEDOT film $\left(7.44 \times 10^{-2} \mathrm{~S} / \mathrm{m}\right)$. The difference of the conductivity of the films is small, which is attributed to the bulk doping of the PEDOT film. In addition, a Kelvin probe was used to determine the WF of the films, and the results show that the WF of the dipolar film was $5.2 \mathrm{eV}$ and that of PEDOT was $4.9 \mathrm{eV}$. The WF of PEDOT was higher than its HOMO, resulting from the partially doped state. The increased WF of the dipolar film is attributed to the permanent dipole formed between the PEDOT cation layer and the F4TCNQ anion layer.

The PSCs were fabricated with the device structure of ITO/dipolar interface or PEDOT $(25 \mathrm{~nm}) / \mathrm{PTB} 7: \mathrm{PC}_{71} \mathrm{BM}$ $(90 \mathrm{~nm}) / \mathrm{PFN}-\mathrm{Br}(5 \mathrm{~nm}) / \mathrm{Al}(100 \mathrm{~nm})$. The thickness of dipolar interfaces was optimized as shown in Figure S5 


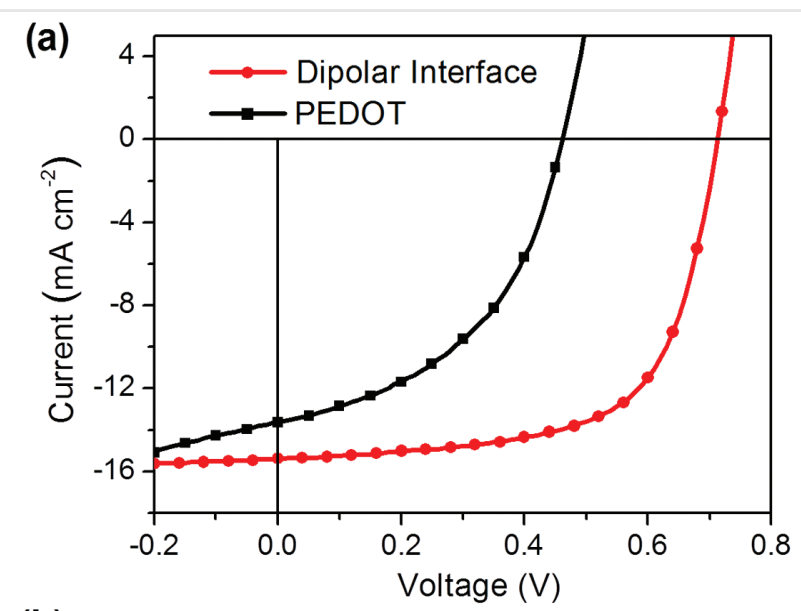

(b)

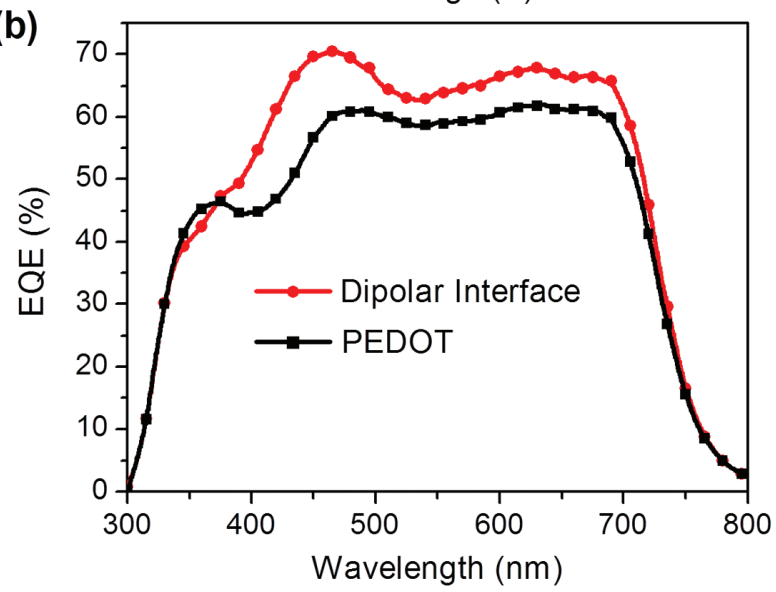

Figure 4 (a) J-V characteristics of the PSCs based on different anode interlayers under $1000 \mathrm{~W} \mathrm{~m}^{-2} \mathrm{AM} 1.5 \mathrm{G}$ illumination. (b) EQE curves. The device structure is ITO/anode interlayer $(\sim 25 \mathrm{~nm}) /$ PTB7:PC71BM $(90 \mathrm{~nm}) / \mathrm{PFN}-\mathrm{Br}(5 \mathrm{~nm}) / \mathrm{Al}(100 \mathrm{~nm})$.

and Table S1. PFN-Br is a typical cathode material behaving as an electron transport interface. ${ }^{56}$ As shown in Figure 4a and Table 1, the devices based on the dipolar interface showed an enhanced power conversion efficiency (PCE) of $7.09 \%$, which is much higher than that of the PEDOT-based device (PCE of 2.91\%). All the three factors including the short-circuit current $\left(J_{\mathrm{SC}}\right)$, open circuit voltage $\left(V_{\mathrm{oc}}\right)$, and $\mathrm{FF}$ were increased, resulting in the improved PCE. Especially, the $V_{\text {oc }}$ dramatically increased from $0.46 \mathrm{~V}$ in the PEDOT- based device to $0.71 \mathrm{~V}$ in the dipolar-interface-based device, which must be related to the special interface dipole. In addition, the methodology also works well in different material systems such as nonfullerene materials. We fabricated solar cells comprising nonfullerene active layer PM7:IT4F (Figure S1), which showed similar enhancements especially in $V_{\text {oc }}$ and FF and a distinct promotion of PCE from $2.01 \%$ to $9.22 \%$ (Table 1 and Figure S7). The main factor of the increased $V_{\text {oc }}$ was attributed to the increased WF of the anode modified with the dipolar thin film. According to the literature, the HOMO level of thieno[3,4-b]thiophene/ benzodithiophene (PTB7) is located at $5.2 \mathrm{eV} .{ }^{47}$ As for the PEDOT interlayer with the WF of $4.9 \mathrm{eV}$, it builds Schottky contacts with active layers, which would cause voltage loss. However, the dipolar interface with a WF of $5.2 \mathrm{eV}$ may build ohmic contacts, which would avoid the voltage loss and then an increased $V_{\text {oc }}$ was obtained. So, the interface dipole plays an essential role in tuning WF and further increases the device performance. The FF was also dramatically increased from $46.41 \%$ to $64.94 \%$ by using the dipolar interface, which clearly indicates the enhanced hole extraction ability of this novel interlayer. The $J_{\mathrm{sc}}$ value of the dipolar-interface-based device was increased from 13.65 to $15.38 \mathrm{~mA} \mathrm{~cm}^{-2}$, which could be also attributed to the better contact between the dipolar interlayer and the active layer. External quantum efficiency (EQE) curves are given in Figure $4 \mathrm{~b}$, showing that devices with the dipolar interface possess higher EQEs in the whole visible-light region. Here the integrated currents from the EQE curves were under $3 \%$ error relative to $J-V$ data. The dark current curves for the devices based on different anode interlayers are shown in Figure S6. Devices with the dipolar interface showed decreased dark currents under a reversed bias and an increased rectification ratio, which is beneficial for charge selectivity and transportation.

Mott-Schottky (MS) analysis was performed as shown in Figure 5a, showing a linear region at the moderate bias region, representing the formation of Schottky contacts and the capacitance of the depletion layer. The built-in potential $\left(V_{\mathrm{BI}}\right)$ and density of impurity $(N)$ were calculated by linear fitting according to the MS equation: $\mathrm{C}^{-2}=\left(2 / q_{\mathrm{r} 0} N\right)\left(V_{\mathrm{BI}}-V\right)$, where $q$ is the elementary charge, ${ }_{0}$ is the permittivity of vacuum, and ${ }_{r}$ is the permittivity of devices $(>>3)$. The fitting results of $V_{\mathrm{BI}}$ and $N$ for the PEDOT-based device are $0.58 \mathrm{~V}$ and

Table 1 Performance of devices with different anode interlayers under $1,000 \mathrm{~W} \mathrm{~m}^{-2}$ AM illumination

\begin{tabular}{llllll}
\hline Anode interlayer & Active layer & $V_{\text {oc }}(\mathrm{V})$ & JSC $\left(\mathrm{mA} \mathrm{cm}^{-2}\right)$ & FF (\%) & Average PCE (\%) \\
\hline PEDOT & PTB7:PC 71 BM & $0.46 \pm 0.01$ & $13.65 \pm 0.24$ & $46.41 \pm 1.04$ & $2.91 \pm 0.14$ \\
& PM7:IT4F & $0.25 \pm 0.01$ & $15.36 \pm 2.02$ & $52.39 \pm 1.90$ & $2.01 \pm 0.29$ \\
Dipolar interface & PTB7:PC 71 BM & $0.71 \pm 0.01$ & $15.38 \pm 0.16$ & $64.94 \pm 0.79$ & $7.09 \pm 0.09$ \\
& PM7:IT4F & $0.82 \pm 0.01$ & $16.58 \pm 0.19$ & $67.61 \pm 1.98$ & $9.22 \pm 0.71$ \\
\hline
\end{tabular}

Note: Statistical data were obtained and averaged from 12 independent devices. 


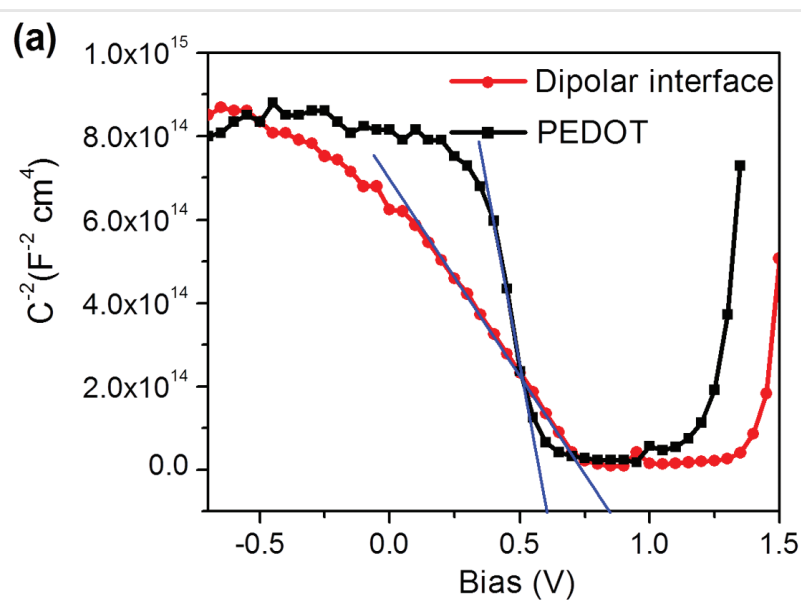

(b)

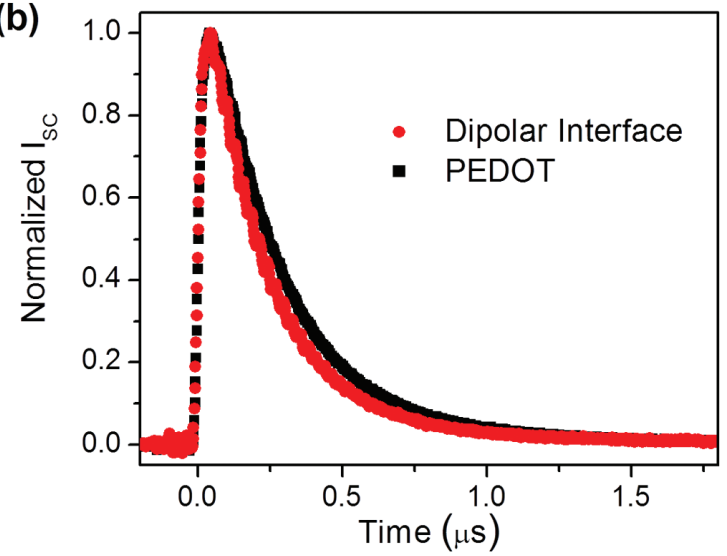

Figure 5 (a) Mott-Schottky (MS) analysis for the devices based on two different anode interlayers. Measurements were conducted in the dark circumstance and $1 \mathrm{KHz}$ AC signal. (b) TPC as a function of time for the PSCs in the TPC measurement. The device structure is ITO/anode interlayer $(\sim 25 \mathrm{~nm}) / \mathrm{PTB7}: \mathrm{PC71BM}(90 \mathrm{~nm}) / \mathrm{PFN}-\mathrm{Br}(5 \mathrm{~nm}) / \mathrm{Al}$ $(100 \mathrm{~nm})$.

$4.70 \times 10^{15} \mathrm{~cm}^{-3}$, and those for the dipolar-interface-based device are $0.83 \mathrm{~V}$ and $1.55 \times 10^{16} \mathrm{~cm}^{-3}$, respectively. The much higher built-in potential in the dipolar-based device corresponds well to the higher $V_{\mathrm{oc}}$, which is originated from the increased WF of the anode after modification by the dipolar interface. Similar to our recently reported results that an increased $V_{\text {oc }}$ was obtained when a dipolar cathode interlayer was used in an inverted PSC, ${ }^{39}$ we can also attribute to an interface dipole induced increase of WF at the anode interface that enables ohmic contacts between the dipolar interface and active layers for the enhancement of the $V_{\mathrm{BI}}$. In addition, the increased $N$ value is responsive to the enhanced $J_{\mathrm{SC}}$ in the dipolar-interface-based device. Then, transient photocurrents (TPCs) were performed to explore the charge extraction process in the devices based on two different anode interlayers (Figure 5b). The charge extraction lifetime decreased from $3.9 \mu$ s for devices with PEDOT to $2.4 \mu$ s for devices with the
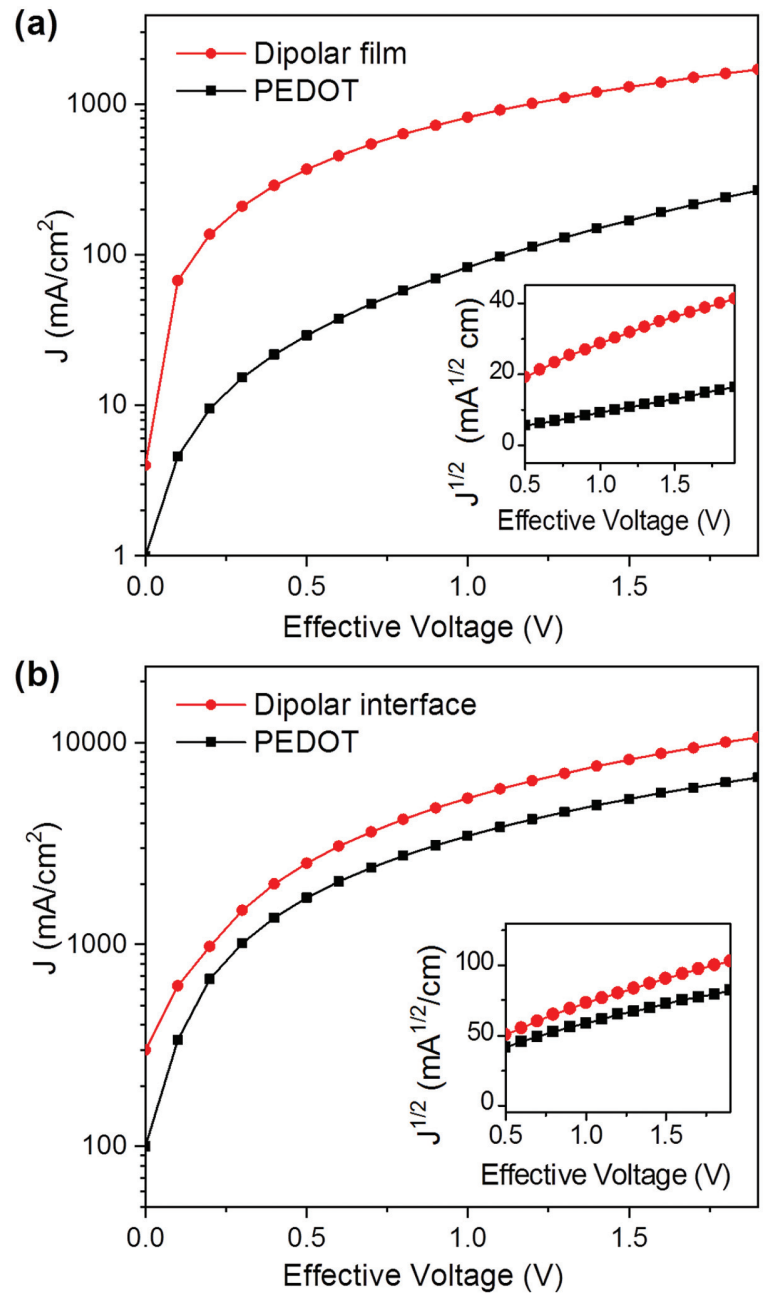

Figure $6 \mathrm{~J}-V$ curves of the hole-only devices for the (a) ITO/dipolar film or PEDOT $(100 \mathrm{~nm}) / \mathrm{MoO}_{3} / \mathrm{Al}$ and (b) ITO/dipolar interface or PEDOT $(25 \mathrm{~nm}) / \mathrm{PTB} 7: \mathrm{PC} 71 \mathrm{BM} / \mathrm{MoO}_{3} / \mathrm{Al}$. The insets are $J^{1 / 2}-V$ curves of the hole-only devices.

dipolar interface. The shorter charge extraction time in the dipolar-interface-based device meant improved charge extraction properties, which is related to the increased $V_{\mathrm{BI}}$, leading to a higher $J_{\mathrm{sc}}$.

To further explore the influence of interface dipole on charge carrier transport properties, we fabricated hole-only devices of solo interfaces and the interface layer together with the active layer. The configuration structures of these two types of hole-only devices were ITO/dipolar interface or PEDOT $(100 \mathrm{~nm}) / \mathrm{MoO}_{3}(10 \mathrm{~nm}) / \mathrm{Al}(100 \mathrm{~nm})$, and ITO/dipolar interface or PEDOT(25 nm)/PTB7: $\mathrm{PC}_{71} \mathrm{BM}(90 \mathrm{~nm}) / \mathrm{MoO}_{3}(10 \mathrm{~nm}) /$ Al $(100 \mathrm{~nm})$. As shown in Figure 6a, the hole mobility of dipolar interface was calculated to be $6.00 \times 10^{-5} \mathrm{~cm}^{2} \mathrm{~V}^{-1} \mathrm{~s}^{-1}$, which is much higher than the value obtained in the PEDOT film $\left(1.54 \times 10^{-5} \mathrm{~cm}^{2} \mathrm{~V}^{-1} \mathrm{~s}^{-1}\right)$. The increased hole mobility in the dipolar interface would benefit the extraction and 
transport of hole carriers in the interface, and lower the recombination possibility of holes and electrons, resulting in better device performance in PSCs. In the hole-only devices of the interlayer together with the active layer, the hole mobility increased from $3.21 \times 10^{-4}$ to $5.54 \times 10^{-4} \mathrm{~cm}^{2} \mathrm{~V}^{-1} \mathrm{~s}^{-1}$ when PEDOT was replaced with the dipolar interface. The result intuitionally confirmed the significant effect of the dipolar interface on the increase of hole mobility in PSCs, which led to higher $J_{\mathrm{SC}}$ and FF.

\section{Conclusions}

In conclusion, we have successfully fabricated a kind of dipolar interface via surface doping of PEDOT with F4TCNQ to build interface dipoles. The dipolar interface showed a smooth morphology, a good conductivity, and an increased WF. When applied as an anode interface in PSCs, the $V_{\text {oc }}$ of the device dramatically increased owing to the ohmic contacts between the dipole interface and the active layer, which was benefited from the increased WF. The increased hole extraction ability of the dipolar interface was demonstrated in the devices due to the formation of the interface dipole. The research results clearly indicate the significant effect of interface dipoles in tuning WF and improving the device performance of PSCs.

\section{Experimental Section}

Materials: All reagents, including EDOT, $\mathrm{TBAPF}_{6}, \mathrm{PTB}$, and [6,6]-phenyl-C71-butyric acid methylester $\left(\mathrm{PC}_{71} \mathrm{BM}\right)$ were purchased from Alfa Aesar or Sigma-Aldrich and used without further purification. The donor polymer PM7 and nonfullerene acceptor IT4F were purchased from Solarmer Materials Inc., and used without further purification.

Device fabrication and measurement: Patterned ITOglass substrates were used as the anode electrode in PSCs. The ITO-coated glass substrates were cleaned in an ultrasonic bath with acetone, a detergent, deionized water, and isopropanol successively, and then dried in a $80{ }^{\circ} \mathrm{C}$ constant-temperature oven. ECP was conducted via the CV method with a CHI760D electrochemical workstation in a three-electrode electrochemical cell, with ITO as the working electrode, titanium metal as the counter electrode, and a $\mathrm{Ag} / \mathrm{Ag}^{+}(0.01 \mathrm{M})$ electrode as the reference electrode. A mixture of $\operatorname{EDOT}(0.01 \mathrm{M})$ and $\mathrm{TBAPF}_{6}(0.1 \mathrm{M})$ in $\mathrm{ACN}$ solvent was applied as the electrolyte solution. The scan range was from 0 to $1.0 \mathrm{~V}$ (vs. $\mathrm{Ag} / \mathrm{Ag}^{+}$), and the scan speed was $200 \mathrm{mV} \mathrm{s}^{-1}$. The thickness of ECP PEDOT was measured by the surface profiler. The F4TCNQ solution of $1 \mathrm{mg} \mathrm{mL}^{-1}$ was spincoated onto PEDOT at the speed of $3000 \mathrm{r} \mathrm{min}^{-1}$. Then the solution of PTB7 blended with $\mathrm{PC}_{71} \mathrm{BM}$ (1:1.5 by weight) in chlorobenzene $(\mathrm{CB})$ with $3 \%$ 1,8-diiodooctane (DIO) was used as the photoactive layer. The solution was spincoated onto the anode interface at the speed of $1400 \mathrm{r}$ $\mathrm{min}^{-1}$, and a $100-\mathrm{nm}$ active layer was obtained. The PFNBr solution of $0.2 \mathrm{mg} \mathrm{ml}^{-1}$ in methanol was spin-coated onto the active layer at the speed of $2000 \mathrm{r} \mathrm{min}{ }^{-1}$. Then $100 \mathrm{~nm}$ of $\mathrm{Al}$ was deposited through a shadow mask (defined active area of $0.16 \mathrm{~cm}^{2}$ ) by thermoevaporation. All device fabrication processes were carried out in a $\mathrm{N}_{2}$-filled glove box. $J-V$ curves and PCEs were measured under an AM 1.5 G solar simulator (Japan, SAN-EI, XES40S1) with a Keithley 2400 source meter. The power of solar simulation was calibrated to be $100 \mathrm{~mW} \mathrm{~cm}^{-2}$ using a standard silicon cell. EQE measurements were conducted via a commercial EQE test system (Enlitech, QE-R, Taiwan). The tests of WF by the Kelvin probe (SKP5050, Scanning Kelvin Probe, UK) were conducted under dark conditions. Hole-only devices: The device structures were ITO/dipolar interface or PEDOT $(100 \mathrm{~nm}) / \mathrm{MoO}_{3}$ $(10 \mathrm{~nm}) / \mathrm{Al}(100 \mathrm{~nm})$ for solo interfaces and ITO/dipolar interface or PEDOT $(25 \mathrm{~nm}) / \mathrm{PTB}_{\mathrm{P}}: \mathrm{PC}_{71} \mathrm{BM}$ $(100 \mathrm{~nm}) / \mathrm{MoO}_{3}(10 \mathrm{~nm}) / \mathrm{Al}(100 \mathrm{~nm})$ for whole devices. The hole mobility was calculated by the space-charge limited current (SCLC) model equation: $J=(9 / 8) \varepsilon_{0} \varepsilon_{\mathrm{r}} \mu$ $\left[\left(V^{2}\right) /\left(d^{3}\right)\right]$, where $J$ is the current density, $\varepsilon_{0}$ is the permittivity of vacuum, $\varepsilon_{\mathrm{r}}$ is the relative permittivity, $\mu$ is the zero-field mobility, $V$ is the effective voltage, and $d$ is the thickness of layers between the anode and cathode electrodes.

\section{Funding Information}

National Natural Science Foundation of China (21733005, 21975076, 51521002, 51761135101, 51873068), the Fund of the Key Laboratory of Luminescence from Molecular Aggregates of Guangdong Province (2019B030301003), and Key Program of Guangzhou Scientific Research Special Project (201707020024, 201904020035).

\section{Acknowledgment}

We acknowledge Prof. Yuguang Ma from State Key Laboratory of Luminescent Materials and Devices for the helpful discussions about electrochemical depositions of PEDOT onto ITO electrodes.

\section{Supporting Information}

Supporting Information for this article is available online at https://doi.org/10.1055/s-0040-1702933. 


\section{References}

(1) Yu, G.; Gao, J.; Hummelen, J. C.; Wudl, F.; Heeger, A. J. Science 1995, 270, 1789.

(2) Cheng, P.; Li, G.; Zhan, X. W.; Yang, Y. Nat. Photonics 2018, 12, 131.

(3) Zhang, Z.; Tan, H. S.; Guo, X.; Facchetti, A.; Yan, H. Nat. Energy 2018, 3, 720 .

(4) Hou, J.; Inganäs, O.; Friend, R. H.; Gao, F. Nat. Mater. 2018, 17, 119.

(5) Ye, L.; Hu, H.; Ghasemi, M.; Wang, T.; Collins, B. A.; Kim, J. H.; Jiang, K.; Carpenter, J. H.; Li, H.; Li, Z.; McAfee, T.; Zhao, J.; Chen, X.; Lai, J. L. Y.; Ma, T.; Bredas, J. L.; Yan, H.; Ade, H. Nat. Mater. 2018, 17, 253.

(6) Sun, C. K.; Pan, F.; Chen, S. S.; Wang, R.; Sun, R.; Shang, Z. Y.; Qiu, B. B.; Min, J.; Lv, M. L.; Meng, L.; Zhang, C. F.; Xiao, M.; Yang, C. D.; Li, Y. F. Adv. Mater. 2019, 31, 1905480.

(7) Yuan, J.; Zhang, Y.; Zhou, L.; Zhang, G.; Yip, H. L.; Lau, T. K.; Lu, X.; Zhu, C.; Peng, H.; Johnson, P. A.; Leclerc, M.; Cao, Y.; Ulanski, J.; Li, Y.; Zou, Y. Joule 2019, 3, 1140.

(8) Fan, B. B.; Zhang, D. F.; Li, M. J.; Zhong, W. K.; Zeng, Z. M. Y.; Ying, L.; Huang, F.; Cao, Y. Sci. China Chem. 2019, 62, 746.

(9) Cui, Y.; Yao, H.; Hong, L.; Zhang, T.; Xu, Y.; Xian, K.; Gao, B.; Qin, J.; Zhang, J.; Wei, Z.; Hou, J. Adv. Mater. 2019, 31, 1808356.

(10) Lin, Y.; Wang, J.; Zhang, Z. G.; Bai, H.; Li, Y.; Zhu, D.; Zhan, X. Adv. Mater. 2015, 27, 1170.

(11) Zhou, Z. C.; Xu, S. J.; Song, J. N.; Jin, Y. Z.; Yue, Q. H.; Qian, Y. H.; Liu, F.; Zhang, F. L.; Zhu, X. Z. Nat. Energy 2018, 3, 952.

(12) Gao, K.; Li, L.; Lai, T.; Huang, Y.; Huang, F.; Peng, J.; Cao, Y.; Liu, F.; Russell, T. R.; Janssen, R. A. J. Am. Chem. Soc. 2015, 137, 7282.

(13) Gao, K.; Miao, J.; Xiao, L.; Deng, W.; Kan, Y.; Liang, T.; Wang, C.; Huang, F.; Peng, J.; Cao, Y.; Liu, F.; Russell, T. P.; Wu, H.; Peng, X. Adv. Mater. 2016, 28, 4727.

(14) Gao, K.; Zhu, Z.; Xu, B.; Jo, S. B.; Kan, Y.; Peng, X.; Jen, A. K. Adv. Mater. 2017, 29, 1703980.

(15) Xie, Z.; Würthner, F. Adv. Energy Mater. 2017, 7, 1602573.

(16) Wu, Z.; Sun, C.; Dong, S.; Jiang, X. F.; Wu, S.; Wu, H.; Yip, H. L.; Huang, F.; Cao, Y. J. Am. Chem. Soc. 2016, 138, 2004.

(17) Wen, X.; Nowak-Król, A.; Nagler, O.; Kraus, F.; Zhu, N.; Zheng, N.; Müller, M.; Schmidt, D.; Xie, Z.; Würthner, F. Angew. Chem. Int. Ed. 2019, 58, 13051.

(18) Rivnay, J.; Inal, S.; Collins, B. A.; Sessolo, M.; Stavrinidou, E.; Strakosas, X.; Tassone, C.; Delongchamp, D. M.; Malliaras, G. G. Nat. Commun. 2016, 7, 11287.

(19) De Jong, M. P.; Van Ijzendoorn, L. J.; De Voigt, M. J. A. Appl. Phys. Lett. 2000, 77, 2255.

(20) Turak, A. RSC Adv. 2013, 3, 6188.

(21) Arora, S.; Kumar Rajouria, S.; Kumar, P.; Bhatnagar, P. K.; Arora, M.; Tandon, R. P. Phys. Scr. 2011, 83, 035804.

(22) Wong, K. W.; Yip, H. L.; Luo, Y.; Wong, K. Y.; Lau, W. M.; Low, K. H.; Chow, H. F.; Gao, Z. Q.; Yeung, W. L.; Chang, C. C. Appl. Phys. Lett. 2002, 80, 2788.

(23) Rafique, S.; Abdullah, S. M.; Shahid, M. M.; Ansari, M. O.; Sulaiman, K. Sci. Rep. 2017, 7, 39555.

(24) Chen, M-C.; Chiou, Y-S.; Chiu, J-M.; Tedla, A.; Tai, Y. Marked. J. Mater. Chem. A 2013, 1, 3680.

(25) Nguyen, T. P.; Le Rendu, P.; Long, P. D.; De Vos, S. A. Surf. Coat. Tech. 2004, 180-181, 646.

(26) Kim, H. Y.; Sachse, C.; Hermenau, M.; Fehse, K.; Riede, M.; Müller-Meskamp, L.; Leo, K. Appl. Phys. Lett. 2011, 99, 113305.

(27) Kim, H.; Nam, S.; Lee, H.; Woo, S.; Ha, C-S.; Ree, M.; Kim, Y.J. Phys. Chem. C 2011, 115, 13502.
(28) Shao, S.; Liu, J.; Bergqvist, J.; Shi, S.; Veit, C.; Würfel, U.; Xie, Z.; Zhang, F. Adv. Energy Mater. 2013, 3, 349.

(29) Choi, H.; Kim, H. B.; Ko, S. J.; Kim, J. Y.; Heeger, A. J. Adv. Mater. 2015, 27, 892.

(30) Murray, I. P.; Lou, S. J.; Cote, L. J.; Loser, S.; Kadleck, C. J.; Xu, T.; Szarko, J. M.; Rolczynski, B. S.; Johns, J. E.; Huang, J.; Yu, L.; Chen, L. X.; Marks, T. J.; Hersam, M. C. J. Phys. Chem. Lett. 2011, 2, 3006.

(31) Liu, Y.; Duzhko, V. V.; Page, Z. A.; Emrick, T.; Russell, T. P. Acc. Chem. Res. 2016, 49, 2478.

(32) He, Z.; Zhong, C.; Huang, X.; Wong, W. Y.; Wu, H.; Chen, L.; Su, S.; Cao, Y. Adv. Mater. 2011, 23, 4636.

(33) Zhou, D.; Cheng, X.; Xu, H.; Yang, H.; Liu, H.; Wu, F.; Chen, L.; Chen, Y. J. Mater. Chem. A 2016, 4, 18478.

(34) Xu, H.; Lu, Z.; Ding, Z.; Hu, J.; Liu, J.; Liu, Y. Nano Res. 2018, 11, 4293.

(35) Dong, S.; Zhang, K.; Liu, X.; Yin, Q.; Yip, H. L.; Huang, F.; Cao, Y. Sci. China Chem. 2019, 62, 67.

(36) Zhang, Z-G.; Qi, B.; Jin, Z.; Chi, D.; Qi, Z.; Li, Y.; Wang, J. Energy Environ. Sci. 2014, 7, 1966.

(37) O’Malley, K. M.; Li, C-Z.; Yip, H-L.; Jen, A. K-Y. Adv. Energy Mater. 2012, 2, 82 .

(38) Lin, X.; Jumabekov, A. N.; Lal, N. N.; Pascoe, A. R.; Gomez, D. E.; Duffy, N. W.; Chesman, A. S. R.; Sears, K.; Fournier, M.; Zhang, Y.; Bao, Q.; Cheng, Y-B.; Spiccia, L.; Bach, U.Nat. Commun. 2017, 8, 613.

(39) Ma, W.; Luo, Y.; Nian, L.; Wang, J.; Wen, X.; Liu, L.; Hanif, M.; Xie, Z.; Ma, Y. ACS Appl. Mater. Interfaces 2018, 10, 10513.

(40) Wang, R.; Nian, L.; Yao, L.; Liu, L.; Xie, Z.; Ma, Y. ACS Appl. Mater. Interfaces 2016, 8, 26463.

(41) Lv, Y.; Yao, L.; Gu, C.; Xu, Y.; Liu, D.; Lu, D.; Ma, Y. Adv. Energy Mater. 2011, 21, 2896.

(42) Gu, C.; Chen, Y.; Zhang, Z.; Xue, S.; Sun, S.; Zhang, K.; Zhong, C.; Zhang, H.; Pan, Y.; Lv, Y.; Yang, Y.; Li, F.; Zhang, S.; Huang, F.; Ma, Y. Adv. Mater. 2013, 25, 3443.

(43) Feng, T.; Xiao, B.; Lv, Y.; Xie, Z.; Wu, H.; Ma, Y. Chem. Commun. 2013, 49, 6283.

(44) Debiemme-Chouvy, C. Electrochem. Commun. 2009, 11, 298.

(45) Ma, W.; Qin, L.; Gao, Y.; Zhang, W.; Xie, Z.; Yang, B.; Liu, L.; Ma, Y. Chem. Commun. 2016, 52, 13600.

(46) Gu, C.; Huang, N.; Chen, Y.; Zhang, H.; Zhang, S.; Li, F.; Ma, Y.; Jiang, D. Angew. Chem. Int. Ed. 2016, 55, 3049.

(47) Gu, C.; Zhang, Z.; Sun, S.; Pan, Y.; Zhong, C.; Lv, Y.; Li, M.; Ariga, K.; Huang, F.; Ma, Y. Adv. Mater. 2012, 24, 5727.

(48) Chen, W.; Qi, D.; Gao, X.; Wee, A. T. S. Prog. Surf. Sci. 2009, 84, 279.

(49) Ivanović, M.; Peisert, H.; Chassé, T. Org. Electron. 2016, 39, 267.

(50) Martinez, J. I.; Flores, F.; Ortega, J.; Rangan, S.; Ruggieri, C.; Bartynski, R. J. Phys. Chem. C 2015, 119, 22086.

(51) Yan, H.; Manion, J. G.; Yuan, M.; Garcia de Arquer, F. P.; McKeown, G. R.; Beaupre, S.; Leclerc, M.; Sargent, E. H.; Seferos, D. S. Adv. Mater. 2016, 28, 6491.

(52) Liu, D.; Li, Y.; Yuan, J.; Hong, Q.; Shi, G.; Yuan, D.; Wei, J.; Huang, C.; Tang, J.; Fung, M-K. J. Mater. Chem. A 2017, 5, 5701.

(53) Saito, Y.; Fukuri, N.; Senadeera, R.; Kitamura, T.; Wada, Y.; Yanagida, S. Electrochem. Commun. 2004, 6, 71.

(54) Groenedaal, L.; Jonas, F.; Freitag, D.; Pielartzik, H.; Reynolds, J. R. Adv. Mater. 2000, 12, 481.

(55) Ma, L.; Hu, P.; Jiang, H.; Kloc, C.; Sun, H.; Soci, C.; Voityuk, A. A.; Michel-Beyerle, M. E.; Gurzadyan, G. G. Sci. Rep. 2016, 6, 28510

(56) Ohisa, S.; Kato, T.; Takahashi, T.; Suzuki, M.; Hayashi, Y.; Koganezawa, T.; McNeill, C. R.; Chiba, T.; Pu, Y. J.; Kido, J. ACS Appl. Mater. Interfaces 2018, 10, 17318. 